\title{
Dialogismo na produção de sentidos em leitura de textos escritos
}

\author{
Dialogism in the production of meanings in reading of written texts
}

\section{Dialogismo en la producción de sentido en la lectura de textos escritos}

\author{
Ângela Alves de Araújo Barbosa ${ }^{1}$ (iD https://orcid.org/0000-0002-5730-3876 \\ Keilla Rebeka Simões Oliveira de Freitas ${ }^{2}$ iD https://orcid.org/0000-0002-3799-565X \\ Sandra Patrícia Ataíde Ferreira ${ }^{3}$ (iD https://orcid.org/0000-0003-3055-789X \\ Fabíola Mônica da Silva Gonçalves ${ }^{4}$ (iD) https://orcid.org/0000-0002-4329-7372
}

\begin{abstract}
RESUMO: Objetivou-se discutir uma proposta analítica na investigação da produção de sentidos em leituras de textos escritos a partir da teoria dialógica da linguagem (BAKHTIN, 1997, 2002; BARBOSA, 2014). Esta proposta analítica volta-se para a interpretação do movimento dialógico de antecipação e apropriação do discurso do outro e foi aplicada para a compreensão de dois diferentes contextos de pesquisa sobre a leitura: um envolvendo um estudante universitário, na produção de diários de leitura; e o outro, crianças da educação infantil em rodas de leitura. Os resultados indicam que a proposta permite interpretar as rotas/mudanças de sentido na compreensão de textos escritos na interlocução de diferentes leitores. Sugere-se que esta proposta analítica seja aplicada a outras situações de produção de sentido em leitura, com diferentes sujeitos e gêneros do discurso escrito/multimodal.
\end{abstract}

PALAVRAS-CHAVE: Proposta analítica. Leitura. Produção de sentido. Diálogo.

\begin{abstract}
We discuss the analytical proposal in the investigation of the production of meanings in readings of written texts, in context of situated practice, based on the dialogical theory of Language (BAKHTIN, 1997, 2002; BARBOSA, 2014). The analytical proposal turns to the dialogical movement of anticipation and appropriation of the other's discourse applied to the understanding of two different contexts of research about reading: one involving one university student in the production of reading diaries; and the other, kindergarten children, in reading circles. The results indicate that the proposal allows to interpret the routes/ changes of meaning

\footnotetext{
${ }^{1}$ Doutoranda em Ciências da Linguagem, bolsista CAPES/PROSUC. Universidade Católica de Pernambuco. E-mail: aangelaraujo@gmail.com

2 Doutoranda em Psicologia Cognitiva, bolsista CNPq. Professora Substituta da Universidade Federal da Paraíba. E-mail: keilla.rso@gmail.com

${ }^{3}$ Doutora em Psicologia Cognitiva. Professora Associada da Universidade Federal de Pernambuco. E-mail: tandaa@terra.com.br

4 Doutora em Psicologia Cognitiva. Professora da Universidade Estadual da Paraíba. E-mail: francesfabiola@gmail.com
} 
in the comprehension of written texts in the dialogue of different readers. It is suggested that this analytical proposal be applied to other situations of meaning production in reading situation, with different subjects and genres of written / multimodal discourse.

KEYWORDS: Analytical proposal. Reading. Production of meaning. Dialogue.

RESUMEN: Se tiene como objetivo una propuesta analítica en la investigación de la producción de sentidos en lecturas de textos escritos a partir de la teoría dialógica del linguaje (BAKHTIN, 1997, 2002; BARBOSA, 2014). Esta propuesta analítica se ha focado en la interpretación del movimiento dialógico de anticipación y apropiación del discurso del otro y fué aplicada para la comprensión de dos contextos diferentes de investigación sobre la lectura; uno se desarrolla con un estudiante universitário, en la producción de diários de lectura; y el otro con niños de la Educación Infantil, em círculos de lectura. Los resultados indican que la propuesta permite interpretar las rutas/cambios de sentido en la compreensión de textos escritos en la interlocución de diferentes lectores. Se sugiere que esta propuesta analítica se aplique a otras situaciones de producción de setindos en lectura, con diferentes temas y géneros de discurso escrito / multimodal.

PALABRAS CLAVE: Propuesta analítica. Lenguaje. Lectura. Producción de sentido. Diálogo.

\section{Introdução}

Falar de uma sociedade complexa como a atual é falar da participação cidadã crítica, ética, estética e inclusiva, que presume um projeto de educação com ênfase em um aprendizado ao longo da vida (UNESCO, 2017) que visa ao desenvolvimento de sujeitos capazes de autorregular a própria aprendizagem. Nesse contexto, o ensino e a aprendizagem da língua também são problematizados, trazendo para o debate, entre outras questões, a importância da articulação da análise linguística com os outros domínios da língua para promover o desenvolvimento de leitores e produtores de textos críticos e capazes de lidar com diferentes contextos de uso da linguagem.

Desse modo, busca-se, neste artigo, especificamente, enfatizar o domínio do ensino e da aprendizagem da leitura para o entendimento da produção de sentidos, que acontece na interação dialógica que se efetiva entre interlocutores participantes desse tipo de situação comunicativa, (re)pensando o lugar da língua nesse tipo de atividade. Logo, pressupõe-se (i) que a linguagem se materializa por meio de enunciados concretos que articulam os aspectos interno e externo à língua para dar conta da vida vivida do sujeito, situado em tempo e espaço determinados (BAKHTIN, 1997); (ii) que a produção de sentido em leitura de textos escritos não se refere apenas à semiótica das palavras, mas à ideologia, à posição valorativa assumida pelo sujeito (FARACO, 2007); (iii) que o linguístico não se expressa unicamente como unidades formais da língua, mas também em forma de gênero de discurso, como o diálogo face a face em sala de aula ou as sequências dentro de um discurso (BAKHTIN, 1997; MEDVIÉDEV, 2012); (iv) que propostas metodológicas que buscam a compreensão da produção de sentidos em uma perspectiva dialógica podem favorecer o debate sobre processos de mediação para a formação 
humana no domínio da leitura em articulação com os outros domínios do ensino da língua.

Assim, este artigo tem por objetivo descrever a proposta analítica de investigação da produção de sentidos em leituras de textos escritos, no processo de interpretação responsiva, em práticas situadas de ensino e aprendizagem da leitura. Essa discussão está baseada nos recortes de duas investigações, sendo a primeira a dissertação intitulada $\mathrm{O}$ agir de produção de sentidos no processo de interpretação em diários de leitura/blog por estudante universitário (BARBOSA, 2014), da qual resultou a construção da proposta analítica aqui em relevo; e a segunda, derivada da dissertação intitulada Compreensão de textos literários na educação infantil: rodas de leitura e mediação docente (OLIVEIRA, 2017), que levou a cabo a mesma proposta analítica em um contexto diferenciado.

\section{Marco Teórico}

Texto texto Para a discussão que aqui se pretende, assume-se o ponto de vista da língua/linguagem fundamentado no pensamento bakhtiniano, bem como se entende, ainda tendo como fundamento os pressupostos dessa perspectiva, que o esforço de elaboração de uma análise metodológica é condição inalienável da construção epistemológica (MACHADO, 2010). Por isso, pretende-se, de modo mais amplo, refletir sobre a adequação dessa proposta de interpretação para diferentes contextos da atividade de leitura, entendida aqui como responsividade ao enunciado do outro, como encontro entre dois sujeitos, duas consciências e, portanto, como compreensão dialógica, que é construída em um tempo-espaço histórico determinado (BAKHTIN, 1997).

No que se refere à concepção de língua/linguagem, tomando o viés do dialogismo bakhtiniano, assume-se uma concepção interacionista em que o diálogo é definido como posições axiológicas que se encontram responsivamente ${ }^{5}$, nas fronteiras dos enunciados, que é o lugar de reação de diferentes vozes e de produção de sentidos.

Nesse sentido, a língua é entendida como sendo heterodiscursiva. Vale ressaltar que, nessa perspectiva, a língua é compreendida não como um sistema abstrato de formas gramaticais, mas como enunciados concretos, preenchida ideologicamente, assegurando a compreensão mútua nas diversidades ideológicas. Por isso, "[...] aquilo

\footnotetext{
${ }^{5}$ Linguística: ciência ou ideologia? Palestra ministrada pelo professor Carlos Alberto Faraco no Seminário Bakhtin: Autoria, Axiologia e Heteroglossia, no Auditório G2 da Universidade Católica de Pernambuco, Recife, PE, de 11 a 13/03 2019.
} 
que chamamos de língua é também e principalmente um conjunto indefinido de vozes sociais" (FARACO, 2007, p. 56), uma vez que, aos aspectos formais da língua, se articula o ponto de vista da totalidade do enunciado.

Como afirma Bakhtin (1997), o enunciado/texto tem a característica da bipolaridade, ou seja, ele comporta tanto o que é compreensível para todos, o que é repetível e reproduzível, o sistema da língua, como o que é individual, único e irreproduzível, o que se manifesta na situação e na cadeia de textos, mas que é totalmente realizado através do sistema de signos da língua e no que reside o seu sentido. Nas palavras do autor, "os dois polos são incontestáveis, quer se trate da língua, das línguas potenciais, quer se trate do texto único e irreproduzível" (BAKHTIN, 1997, p. 333). Além disso, afirma que o texto não é um objeto e que, portanto, não se pode eliminar nem neutralizar a segunda consciência que toma conhecimento dele, sendo necessário ir além dos elementos formais da língua para compreendê-lo, pois:

"A relação com a coisa (em sua pura materialidade) não pode ser dialógica (ou seja, não pode assumir a forma da conversação, da discussão, da concordância, etc.). A relação com o sentido é sempre dialógica. O ato de compreensão já é dialógico". (BAKHTIN, 1997, p. 350).

Também são os enunciados, enquanto unidades do discurso interior, que permitem ao sujeito pensar e compreender a realidade sob a forma de uma série de gêneros que constituem a consciência e que se realizam no processo de comunicação social ideológica (MEDVIÉDEV, 2012).

Nesse caso, aquele que pratica o ato de compreensão passa a fazer parte do diálogo inconcluso da vida humana (FARACO, 2007), que acontece pela assunção de uma atitude responsiva, o que the permite o desvelamento dos valores que organiza o evento do qual participa. Portanto, a resposta é o motor das relações dialógicas caracterizadas como relações de sentido, este constituído na dialogicidade e na alteridade (FLORES; TEIXEIRA, 2009), uma vez que é dever do sujeito responder (BAKHTIN, 1993) à palavra do outro, assumindo uma posição axiológica pela atividade de enunciação, que é social e intrinsecamente dialógica.

De acordo com a perspectiva do chamado Círculo de Bakhtin,6 tudo que é ideológico possui um significado; é um signo que funciona sob duas operações: o refletir e o refratar (VOLOSHINOV, 2017). Desse modo, pode-se dizer que, com o signo,

\footnotetext{
${ }^{6}$ Refere-se ao conjunto de obras do Círculo, não apenas a Bakhtin.
} 
o sujeito não apenas descreve o mundo, mas o constrói, o refrata a partir do horizonte apreciativo do seu grupo social. Portanto, significar é refratar, e as significações "[...] são construídas na dinâmica da história e estão marcadas pela diversidade de experiências dos grupos humanos, com suas inúmeras contradições e confrontos de valoração e interesses sociais" (FARACO, 2007, p. 50).

Desse modo, assume-se que ler é significar, é construir um mundo a partir do posicionamento axiológico do sujeito-leitor, dentro de uma esfera de atividade humana, frente a diferentes vozes que se intercruzam nas fronteiras dos enunciados produzidos na torrente da interação verbal. Defende-se ainda que, para conhecer as vozes com as quais esse sujeito se posiciona quando produz sentido sobre a leitura, é imprescindível conhecer o seu grupo social e sua esfera simbólica de atuação. Portanto, assenta-se na noção de identificação do ideológico com o simbólico, como buscou o chamado Círculo de Bakhtin, para investigar, de uma perspectiva materialista, os processos e produtos imateriais da cultura presentes na atividade de leitura, ou seja, as vozes sociais em tensão e debate.

Compreendendo que o dialogismo é uma filosofia e não um modelo analítico e, ao mesmo tempo, sabendo da importância de construir procedimentos de análise que considerem os pressupostos dessa teoria sobre a responsividade, apresenta-se aqui uma proposta que visa à compreensão dos complexos de significação através do encontro de enunciados referentes à produção de sentidos em leitura de textos escritos, já que se pressupõe que ler não é apenas atualizar a gramática em um vazio, mas produzir sentidos saturados de valores sociais. Levando em consideração esse propósito, além da presente introdução, o manuscrito está organizado em três principais seç̧ões: (a) descrição da proposta analítica fundamentada no dialogismo; (b) discussão de recortes das investigações que tomaram essa proposta como procedimento de análise; (c) considerações finais que almejam a realização de síntese crítica sobre a proposta analítica de abordagem dialógica para a atividade de leitura.

\section{Proposta analítica dialógica da produção de sentido de textos escritos}

A leitura como ação responsiva está circunscrita no conceito de compreensão ativa, ou seja, implica uma atitude responsiva e responsável em que o leitor/destinatário concorda, discorda, completa, critica, recusa, revaloriza, posiciona-se. Ademais, ao dialogar com os textos, o leitor assume um posicionamento frente ao 
discurso presente e, ao assumi-lo, se responsabiliza por sua produção (BARBOSA, 2014). No dialogismo da leitura, o leitor/agente prepara-se para agir às palavras emitidas pelo locutor/enunciador, o que, segundo Flores e Teixeira (2009), está pressuposto na constituição do sentido - a dialogicidade e a alteridade.

Nesse agir, há concorrência de interação de diversos contextos e pontos de vista, diversas vozes ou "falas sociais" (BAKHTIN, 2002, p. 91). Portanto, na resposta, é amadurecida a compreensão. No movimento responsivo da pessoa leitora (leitoragente), na ação de leitura, há uma reconstrução do enunciado por ela a partir do agir de produção de sentido (BARBOSA, 2014). Esse processo de compreensão ativa implica os movimentos de apropriação do discurso do outro e de antecipação do discurso do outro (BAKHTIN, 2002).

Com relação à apropriação do discurso do outro, considerando-se o dialogismo do discurso, observa-se que grande parte daquilo que é dito foi apropriado e refratado a partir do que foi dito pelo outro, tendo em vista que, cada vez que se produz um enunciado, se participa de um diálogo com outros discursos (FIORIN, 2008). Já a antecipação do discurso do outro é a inclusão de uma voz presumida do seu ouvinte, ainda não pronunciada, antecipando-lhe uma resposta, influenciada por sua percepção sobre o outro que o avalia, portanto uma resposta orientada para os interlocutores. Isso leva em consideração que os enunciados proferidos emergem em um contexto cultural formado por significados e valores, o que envolve uma atitude de posição em relação ao texto (OLIVEIRA, 2017).

Isso posto, a análise proposta focou no posicionamento e na responsividade do locutor enquanto participante do diálogo com o texto, o qual se posiciona responsivamente frente ao discurso do outro. Isso ocorre porque, ao assumir um posicionamento frente ao discurso presente no texto, o locutor participa de um diálogo com ele, compreendendo-o de forma ativa. A responsividade implica posicionamento, marcadamente axiológico, um ato responsável frente ao outro em espaço-tempo histórico e único de cada ser. Assim, a proposta apresentada condensa a unidade posicionamento responsivo. Vale ressaltar que isso se dá por meio da língua, composta pelo movimento de antecipação da resposta do outro (ou palavra do outro) e adoção do discurso do outro (palavra alheia), culminando em apropriação, pois a compreensão ativa implica apropriação do outro - um novo círculo, estando a resposta fundida na compreensão (BARBOSA, 2014). Também foram observados os momentos em que o 
locutor concorda, discorda, completa, critica, recusa, posiciona-se e reposiciona-se em relação ao discurso do outro, como pode ser observado, na proposta de análise, na Figura 1.

Figura 1 - Esquematização do modelo de análise proposto por Barbosa (2014)

\begin{tabular}{|c|c|}
\hline \multicolumn{2}{|c|}{ Análise dialógica do discurso (Barbosa, 2014) } \\
\hline Responsividade & Posicionamento \\
\hline \multicolumn{2}{|c|}{ Posicionamento responsivo } \\
\hline Antecipação da resposta do outro & Apropriação do discurso do outro \\
\hline Concorda, discorda, completa, critic & ecusa, posiciona-se e reposiciona-se \\
\hline Ampliação de sentidos & Mudança de sentidos \\
\hline
\end{tabular}

Fonte: Elaborada pelas autoras (2020).

A partir desse modelo, foi observada a produção dos sentidos produzidos na leitura, em dois diferentes contextos de pesquisa: um envolvendo um estudante universitário na produção de diários de leituras (BARBOSA, 2014); e o outro, crianças da educação infantil interagindo discursivamente acerca dos textos lidos em momentos de rodas de leitura (OLIVEIRA, 2017).

\section{Contextos de investigação: a produção de sentido na leitura}

Primeiro contexto de pesquisa: a leitura de um livro da esfera psicanalítica e a produção de sentidos por um estudante universitário mediadas pelo gênero diário de leituras

Considerando-se o primeiro contexto de pesquisa, situado no Centro de Educação da Universidade de Pernambuco, com Parecer Consubstanciado n. 296.765 do Comitê de Ética em Pesquisa Envolvendo Seres Humanos, a investigação foi direcionada às rotas interpretativas do agente da leitura, em que há uma orientação de/para seu interlocutor, não só respondendo antecipadamente à resposta que este pronunciaria, como também se apropriando do discurso alheio como sendo seu, adaptando-o pela produção de sentidos. Sendo os discursos anteriores ditos preexistentes, são repetidos, porém com a marca daquele que responde-enuncia, aqui, portanto, o leitor. Esse leitor e seus pares tiveram como mediação da leitura a produção de um diário de leituras em ambiente virtual (blog), um gênero do discurso de ordem reflexiva, dialógica e (auto)avaliativa. É um gênero marcado também por 
desenvolvimento de ideias próprias, gerador de autoconfiança frente a materiais de difícil compreensão (MACHADO, 1998).

O contexto sociointeracional de produção da leitura e do diário virtual teve como base o livro Afeto e emoções, da editora Coleção Viver, o qual trata de conceitos psicanalíticos. O participante da pesquisa, cujo nome fictício é Lean, estudante universitário do primeiro período do curso de Pedagogia, foi o primeiro a ter contato com o livro e, tendo como interlocutores os colegas de sala, a professora e alunos universitários de períodos mais adiantados, foi o leitor, autor e produtor do diário virtual. Este teve como título a pergunta precursora dessa produção: $O$ que sentiram ao ler o livro?

Nesse diário [virtual] de leituras, Lean apresenta o movimento de apropriação do discurso do outro em deslocamento de antecipação do discurso do seu ouvinte e de apropriação do discurso do outro já enunciado, sendo este o livro lido e as vozes atravessadas, antes pronunciadas. Os discursos anteriores são assumidos por Lean como seus na produção do diário.

Como analisado em Barbosa (2014), o diário inicia-se com o endereçamento da antecipação à compreensão responsiva do questionamento da professora, título do diário: 0 que sentiram ao ler o livro? Os papéis dos interlocutores influenciam a antecipação à resposta, como também o parâmetro do contexto situacional formal, que está para fins avaliativos de leitura-aprendizagem.

O leitor assume, em seu diário, uma compreensão responsiva daquilo que é esperado pela professora, não respondendo apenas o que sentiu, como questionado, mas ampliando para o que ele aprendeu. Assim, inicia a resposta com (i) "O livro tem uma leitura gostosa e de fácil assimilação"; e (ii) amplia antecipando a resposta em "Aprendi a diferença entre afeto, sentimento e emoção. [...] O livro demonstra que a psicanálise está muito mais presente no nosso dia a dia do que pensamos". Na sua posição de aluno, contorna o diálogo no seu diário com aquilo que foi aprendido por ele, percebendo-se imputado de responsabilidade frente à professora e aos demais pares. Essa antecipação traduz a ressalva diante do julgamento da sua interlocutora principal, a professora. Revela ao seu interlocutor seu estado conceitual anterior à leitura como errado e a implicação do quanto tais conceitos estão interligados e do grau de dificuldade para sua diferenciação, em uma ação responsiva de justificação pelo erro conceitual. Então (iii) prossegue em: "Pra mim, a emoção era algo subjetivo, mas pude 
ver que a emoção pode ser observada através do corpo. [...] Sentimento e emoção estão intimamente ligados".

No entanto, como aprendiz, coloca-se numa posição de aprendizagem dos conceitos, supera a declaração anterior de erro conceitual para a tomada de compreensão dos conceitos pela voz segura e científica da psicanálise, dos quais o livro foi portador, o que se percebe no seguinte ato de posicionamento responsivo: (iv) " $O$ livro demonstra que a psicanálise está muito mais presente no nosso dia a dia [...] pessoas com problemas de personalidade, de sentimentos alterados, etc. Tudo a psicanálise ajuda a resolver". Lean, então, antecipa os critérios de avaliação da professora: compreensão dos conceitos e/ou aprendizagem. Essa antecipação se dá simultaneamente à adoção do discurso do outro - o livro, que é personificado e trazido ao seu discurso de leitura, assim construindo o entendimento sobre (1) o lugar da psicanálise; e (2) os conceitos de sentimento e emoção e suas manifestações. A nova constituição da compreensão do leitor, apoiada no que foi dito no livro, se desloca nestes movimentos: antecipação do discurso e adoção do discurso.

Segundo contexto de pesquisa: compreensão de textos literários em momentos de roda de leitura

Com relação ao segundo contexto de pesquisa, que envolveu um grupo de crianças do último ano da educação infantil interagindo discursivamente em momentos de rodas de leitura, o objetivo foi investigar a compreensão de textos literários em sala de aula, por meio da mediação pedagógica desenvolvida. Para isso, participaram do estudo 20 alunos, na faixa etária dos cinco anos, e a professora da turma observada de um Centro de Referência em Educação Infantil (CREI) que é modelo em atividades de leitura na cidade de João Pessoa/PB.

Para a construção dos dados de pesquisa, após aprovação do Comitê de Ética pelo Parecer Consubstanciado $\mathrm{n}^{0}$ 1.413.622, foram realizadas videografias $\mathrm{e}$ observações dos momentos de leitura em sala de aula. Foram videogravados os momentos de rodas de leitura dos seguintes textos literários escolhidos pela docente: Chapeuzinho vermelho, O patinho feio, Cachinhos Dourados e os três ursos, e Cinderela, de acordo com o planejamento pedagógico. As rodas de leitura consistiam em dois momentos - contação da história pela professora (seguida de perguntas acerca 
do texto) e reconto da mesma história pelas crianças (também seguido de perguntas realizadas pela professora). As videogravações, posteriormente transcritas na íntegra, tiveram a duração estabelecida pela professora, o que era, em média, de 15 minutos. Os nomes escolhidos para os participantes são fictícios, visando preservar sua identidade.

O foco das videografias e observações foram os momentos de trocas comunicativas entre os interlocutores presentes (crianças e professora) no processo de construção de sentidos da leitura, realizado por meio do sistema de signos da língua, indo além de seus elementos formais, no movimento de responder à pergunta realizada pelo outro, de completar a resposta do outro, de perguntar ao outro ou repetir o que foi dito por ele, discorrendo-se acerca da língua em sua forma escrita, presente nos textos lidos. Para a análise das trocas comunicativas entre eles, observando-se o posicionamento e a responsividade do locutor enquanto elaborador de enunciados e participante de um diálogo contínuo com outros enunciados, investigaram-se os movimentos de antecipação da resposta e de apropriação do discurso, verificando-se as situações em que houve ampliação/mudança de sentidos.

Para a análise que será aqui realizada, foram escolhidos os momentos de contação e reconto da história Cachinhos Dourados e os três ursos. A história é composta pela personagem Cachinhos Dourados e uma família formada por três ursos (o pai, a mãe e um filho bebê). De acordo com a narrativa, quando a família de ursos sai de casa para dar uma volta, enquanto esperava que a comida que havia deixado dentro de suas tigelas esfriasse e pudessem comer, Cachinhos Dourados aparece e entra na casa deles ao observar que não havia ninguém lá. Nesse momento, ela prova e/ou come o mingau que estava nas tigelas dos ursos, senta-se nas cadeiras que pertencem aos ursos (momento no qual quebra a cadeira do bebê urso) e se deita nas camas dos ursos, adormecendo na cama do bebê urso. Nesse momento, os ursos voltam para casa e percebem que alguém comeu o mingau deles, sentou-se na cadeira deles e se deitou na cama deles. E em seguida, veem Cachinhos Dourados ainda dormindo na cama do bebê urso, quando ela acorda assustada e corre para a sua casa. A narrativa termina afirmando que ela nunca mais entrou na casa de ninguém sem avisar (BELLI, 2004).

Durante o momento de contação, a professora contou para as crianças a história que estava no livro utilizando suas próprias palavras, sem seguir estritamente o texto 
escrito, mas abordando suas ideias principais. Ao longo dessa situação inicial, as crianças interagiram constantemente entre si e com a professora, respondendo ao que foi perguntado por ela (Professora: "Quando chegaram ao quarto, quem estava dormindo?'; Alunos: "Cachinhos Dourados"); complementando o que foi dito pelo outro (Professora: "E foi pra cama do papai urso"; Victor: "Aqui, tia, ela na cama do papai ursd" - aponta para a imagem do livro); repetindo alguma ação da professora ou algo que ela falou (Professora: "[...] e o bebê urso era bem pequenininho" - levanta a mão na altura do chão; Larissa: "Bem pequenininho"); e pedindo para ver as imagens do livro (Larissa: "Eu quero ver... Cadê?").

Dando continuidade à contação da história, a professora realizou algumas perguntas para as crianças. Estas, inicialmente, expandiram os sentidos do texto ao enfocarem sua aplicação em situações mais próximas do cotidiano, produzindo sentidos dotados de valores sociais, mas centradas em aspectos moralizantes e pedagogizantes, isto é, como forma de os conteúdos de sala serem trabalhados, neste caso, o tema do respeito, como exemplo: "A gente pode entrar na casa das pessoas sem as pessoas tá em casa? [...] A gente pode comer a comida das pessoas sem as pessoas permitirem? [...] E o que Cachinhos Dourados fez não foi legal, ela não tinha autorização pra entrar na casa deles".

Enquanto isso, no momento de reconto da história, a ampliação/mudança de sentidos pôde ser mais observada por meio das trocas discursivas entre os interlocutores. Inicialmente, a professora pediu que uma das crianças da turma, Victor, recontasse a história, o que ele fez a partir da leitura das imagens do livro e da compreensão da contação que havia sido realizada anteriormente pela professora. Durante o reconto, os alunos interagiram frequentemente, posicionando-se responsivamente, apropriando-se do discurso do outro, complementando, concordando ou discordando.

Logo no início, Fernanda afirmou que a casa presente na imagem do livro era feia, e Lucas discordou dizendo que não era. Em seguida, Lucas discordou do termo "mamãe urso" - utilizado por Victor, afirmando ser "mamãe ursa"; e Victor discordou dele dizendo "mamãe urso", termo este que havia sido utilizado pela professora durante o momento anterior de contação, o que remete aos elementos formais de uso da língua. Depois, quando Victor mencionou a cama da mamãe urso e do bebê urso, e demorou para dizer de quem era a próxima cama, Lucas complementou que era a cama 
do papai urso, apontando para a imagem que tinha a cama maior e afirmando ser aquela a maior cama. Victor concordou com ele, repetindo "depois do papai urso".

Nesse momento, as crianças (Victor, Lucas, Larissa e Fernanda) começaram a dialogar sobre o tamanho das três camas. Lucas afirmou que a cama do "papai urso" era a "mais grande", Larissa concordou falando que "o bebê não dorme na cama grande", o que Fernanda completou ao dizer que "é na pequenininhd" e perguntou à professora se "a mamãe dorme numa cama pequena também". Victor respondeu a essa pergunta mostrando para ela a imagem da cama da "mamãe urso" no livro, ao que Larissa completou se esticando para cima e dizendo que aquele era o tamanho da "mamãe urso"; por fim, Lucas completou afirmando que, "na pequena, é o bebê". Desse modo, as crianças ampliaram sentidos relacionados ao tamanho dos ursos de acordo com o personagem (mãe, pai e bebê), relacionando o tamanho deles com a proporção da cama, construindo significações na esfera da interação verbal, refratando questões existentes em seu horizonte social.

Dando continuidade a esse segundo momento, a professora fez algumas perguntas para as crianças, que seguiram participando ativamente. Posteriormente, percebeu-se que Larissa modificou a história contada pela professora ao afirmar que Cachinhos Dourados quebrou a cama do bebê urso, o que não apareceu nas situações anteriores. Na história do livro, o que a personagem quebrava era a cadeira do bebê urso. A professora se apropriou dessa fala como se fizesse parte da história, ampliando o sentido ao questionar: "E por que quebrou?".

Quando a professora fez essa pergunta, Lucas respondeu de acordo com a conclusão chegada ao momento do reconto: "Porque a cama era pequena, era a do bebê", e Larissa se posicionou com relação à situação ocorrida na história, mostrando ter construído o sentido de que as ações de Cachinhos Dourados não foram corretas, ao afirmar que "tem que prender essa menina". Essa afirmação está ligada à noção de punição para reparar os erros, relacionada ao acontecimento narrado pelos discursos sociais e históricos, já que os sentidos atribuídos pelos diversos leitores têm relação com o conhecimento produzido historicamente pelo homem.

Observou-se também que os alunos e a professora se apropriaram do discurso trazido por Victor no reconto de que, quando os ursos chegaram na casa, Cachinhos Dourados correu para a mãe dela, o que foi dito por Larissa e, em seguida, pelos alunos em coro. Também esteve presente na pergunta da professora: "Mas será que ela 
contou pra mamãe dela que fez isso tudinho?', como outra forma para que eles ampliassem os sentidos de que o que a personagem fez foi errado, sendo enfocado novamente por ela ao final desse momento.

Tendo em vista que o processo de compreensão é uma atividade de coautoria, na qual os sentidos do texto também são completados pelo leitor, e levando em consideração a atitude responsiva ativa do ouvinte, que também é locutor (BAKHTIN, 1997), entende-se o discurso trazido por Victor como uma complementação a partir do sentido construído de que o que a personagem fez foi errado e de seus conhecimentos de mundo (correr para a mãe em uma situação de perigo). Tomando a linguagem numa perspectiva dialógica, em que a palavra é sempre perpassada pela palavra do outro (FIORIN, 2008), os interlocutores se apropriaram desse discurso, e a professora tentou ampliar esse sentido a partir da pergunta sobre a mãe da personagem, com o foco, mais uma vez, na questão moral.

Desse modo, em alguns momentos, a antecipação e a apropriação do discurso do outro puderam ser observadas. Também foram descritas as situações em que os locutores concordaram, discordaram, completaram e se posicionaram, interpondo-se diferentes enunciados nas interações verbais. A partir disso, verificou-se que os alunos compreenderam o texto lido e elaboraram significados e sentidos, como exemplo, o tema do respeito pelo que pertence ao outro, a partir dos quais foi produzido o sentido de pedir permissão ao precisar ou desejar usar algo que pertença a alguém; o sentido do tamanho das três camas em proporção ao tamanho dos ursos, enquanto significados e relações que perpassam a história; e uma reflexão acerca das ações da personagem Cachinhos Dourados, entendidas como erradas ao serem comparadas com discursos sociais e históricos. Assim, percebe-se que a proposta analítica em questão permitiu analisar a compreensão do texto e as produções de sentido nas trocas comunicativas entre os alunos, em situação de roda de leitura, em sala de aula.

\section{Considerações Finais}

A proposta analítica elaborada a partir da categoria posicionamento responsivo, delineada pela perspectiva dialógica de Bakhtin, permitiu interpretar as rotas/mudanças de sentidos na compreensão de textos escritos realizadas pelos interlocutores envolvidos, mostrando-se assim adaptada a situações distintas de produção de sentido de textos escritos no/pelo diálogo entre os interlocutores. Nessas situações, as 
unidades da língua funcionam como marcadores de orientação utilizados pelo leitor para a compreensão dos textos, constituindo-se meios para interpretação analítica das pesquisadoras.

Ao assumir o texto escrito como material semiótico que favorece o diálogo entre leitor-autor, foi possível, em dois contextos distintos de práticas de ensino e aprendizagem da leitura, verificar o processo de produção de sentidos realizados pelos leitores, mesmo em níveis de escolaridade diferentes. Como descrito, o primeiro estudo foi desenvolvido com um estudante universitário no contexto de produção de um diário [virtual] de leituras; e o segundo estudo, com alunos da educação infantil no contexto da roda de leitura. Eles apresentam um traço de união que está relacionado ao fato de ambos estarem em contextos de ensino e aprendizagem da leitura, mediados pelo diário de leituras e pela roda de leitura, que visam à participação ativa do leitor e, por conseguinte, à formação do leitor que se posiciona e questiona o escrito pelo autor, que constrói e reconstrói rotas de interpretação, desenvolvendo dessa maneira a criticidade e o posicionamento axiológico perante a vida e os condicionantes sócio-históricos.

Outro ponto de contato é o fato de, nas duas situações, se tratar de leitores que estavam iniciando a aproximação com a leitura de gêneros dos discursos explorados nas referidas pesquisas. $O$ primeiro estudo explorou a produção de sentidos na leitura do gênero do discurso científico, com textos relacionados à teoria psicanalítica, o que, na ocasião, era novidade para o leitor universitário; e no caso da turma da educação infantil, na incursão da leitura do gênero conto, com ricos momentos de trocas comunicativas com o autor do texto e entre os leitores participantes da atividade de ensino e aprendizagem proposta. Nessa direção, observou-se o movimento interpretativo dos leitores de manterem e ampliarem o diálogo com os textos lidos nos contextos em que eles circulam, favorecendo a inserção dos leitores em domínios sociais mais amplos e diferenciados.

Por fim, sugere-se que esta proposta analítica seja aplicada a outras situações de produção de sentido em leitura, com diferentes sujeitos e gêneros do discurso escrito/multimodal, com o objetivo de avaliar a sua eficácia como método analítico elaborado a partir da perspectiva filosófica do chamado Círculo de Bakhtin. 


\section{Referências}

BAKHTIN, Mikhail Mikhailovich. A estética da criação verbal. 2. ed. Tradução de Maria Ermantina Galvão G. Pereira. São Paulo: Martins Fontes, 1997. Original publicado em 1979.

BAKHTIN, Mikhail Mikhailovich. Para uma filosofia do ato. Tradução de Carlos Alberto Faraco e Cristovão Tezza. Austin: University of Texas Press, 1993. Título original: Toward a philosophy of the act. Tradução da edição americana destinada exclusivamente para uso didático e acadêmico.

BAKHTIN, Mikhail Mikhailovich. Questões de literatura e de estética: a teoria do romance. 5. ed. Tradução de Aurora Fornomi Bernardini, José Pereira Júnior, Augusto Góes Júnior, Helena Spryndis Nazário e Homero Freitas de Andrade. São Paulo: Hucitec Annablume, 2002. Original publicado em 1979.

BARBOSA, Ângela Alves de Araújo. O agir de produção de sentidos no processo de interpretação em diários de leitura/blog por estudante universitário. 2014. 158 f. Dissertação (Mestrado em Psicologia Cognitiva) - Departamento de Psicologia, Universidade Federal de Pernambuco, Recife, PE, 2014.

BELLI, Roberto. Cachinhos dourados e os três ursos. Gaspar, SC: Todolivro, 2004. (Série Clássicos de Sempre. BrasiLeitura).

FARACO, Carlos Alberto. O estatuto da análise e da interpretação dos textos no quadro do chamado Círculo de Bakhtin. In: GUIMARÃES, Ana Maria Mattos; MACHADO, Anna Raquel; COUTINHO, Antónia (org.). O interacionismo sociodiscursivo: questões epistemológicas e metodológicas. Campinas, SP: Mercado das Letras, 2007. p. 43-50. (Coleção Ideias sobre Linguagem).

FIORIN, José Luiz. Introdução ao pensamento de Bakhtin. São Paulo: Ática, 2008.

FLORES, Valdir do Nascimento N.; TEIXEIRA, Marlene. Enunciação, dialogismo, intersubjetividade: um estudo sobre Bakhtin e Benveniste. Bakhtiniana: Revista de Estudos do Discurso, São Paulo, v. 1, n. 2, p. 143-164, 2. sem. 2009. Disponível em: https://revistas.pucsp.br/bakhtiniana/article/view/3015. Acesso em: 16 abr. 2018

MACHADO, Anna Rachel. O diário de leituras. a introdução de um novo instrumento na escola. São Paulo: Martins Fontes, 1998.

MACHADO, Irene. A questão espaço-temporal em Bakhtin: cronotopia e exotopia. In: PAULA, Luciane de; STAFUZZA, Grenissa (org.). Círculo de Bakhtin: teoria inclassificável. Campinas: Mercado de Letras, 2010.

MEDVIÉDEV, Pável Nikoláievitch. O método formal nos estudos literários: introdução crítica a uma poética sociológica. Tradução de Sheila Camargo Grillo e Ekaterina Vólkova Américo. São Paulo: Contexto, 2012. Original publicado em 1928.

OLIVEIRA, Keilla Rebeka Simões. Compreensão de textos literários na educação infanti: rodas de leitura e mediação docente. 2017. 168 f. Dissertação (Mestrado em Psicologia 
Cognitiva) - Departamento de Psicologia, Universidade Federal de Pernambuco, Recife, PE, 2017.

UNESCO. Educação para os objetivos de desenvolvimento sustentável: objetivos de aprendizagem. Brasília, DF: Representação da UNESCO no Brasil, 2017. Disponível em: https://ods.imvf.org/wp-content/uploads/2018/12/Recursos-ods-objetivosaprendizagem.pdf. Acesso em: 15 abr. 2018.

VOLOSHINOV, Valentin Nikolaevich. Marxismo e filosofia da linguagem. São Paulo: Editora 34, 2017. Original publicado em 1929. 